\title{
Problems in the assessment of heavy-metal levels in estuaries and the formation of a pollution index
}

\author{
D. L. Tomlinson ${ }^{1}$, J. G. Wilson ${ }^{2}$, C. R. Harris ${ }^{3}$ \& D. W. Jeffrey \\ ${ }^{1}$ School of Botany, ${ }^{2}$ Zoology Department,${ }^{3}$ Geology Department \\ and \\ ${ }^{4}$ School of Botany, Trinity College; Dublin 2, Ireland
}

\begin{abstract}
Most estuaries receive a high heavy-metal input from industries. This is reflected in the relatively high levels found in numerous estuarine organisms and in sediments. Many indicators have been suggested for facilitating the detection of heavy-metal pollution, but the problems in using these indicators to evaluate the metal loading of estuaries are considerable. Variations in species composition, and conditions at different sites, differences in season of sampling, and age of organism, as well as different metal levels in different parts of the organism, make the interpretation of results difficult. The levels reported here, similar to those in other unpolluted estuaries, have been used to suggest a baseline concentration for heavy metals in estuaries. The concept of a baseline is fundamental to the formation of a "Biological Quality Index" and "Pollution Load Index," and a formula for such an index is suggested and tested at a preliminary level against published data for an English and a European estuary.
\end{abstract}

\section{INTRODUCTION}

Inferences drawn from the results of pollution studies in any environment presuppose both a knowledge of the original, unpolluted state of that environment and knowledge of the extent of the natural background changes that would have occurred in the absence of the pollution in question. Such a lack of baseline information has hampered studies of pollution in many British and European estuaries.

The Irish Republic is in a relatively fortunate position in this respect in that, having both a low population ( $<4$ million) and low level of industrialisation, many Irish estuaries remain, for the most part, free from large-scale pollution.

The information presented in this paper derives from a study by the Irish Estuaries Research Programme, an interdisciplinary team employed to investigate the pollution status of estuaries along the east coast of Ireland, the major ones of which are shown in Figure 1.

\section{SOME PROBLEMS IN MEASURING HEAVY METALS IN ESTUARIES}

The water column

A number of problems become immediately apparent in attempting to measure heavy-metal levels in the water column. Firstly, metal concentrations are normally very low $(\mathrm{ppb})$ and thus difficult to measure accurately without sophisticated equipment or 


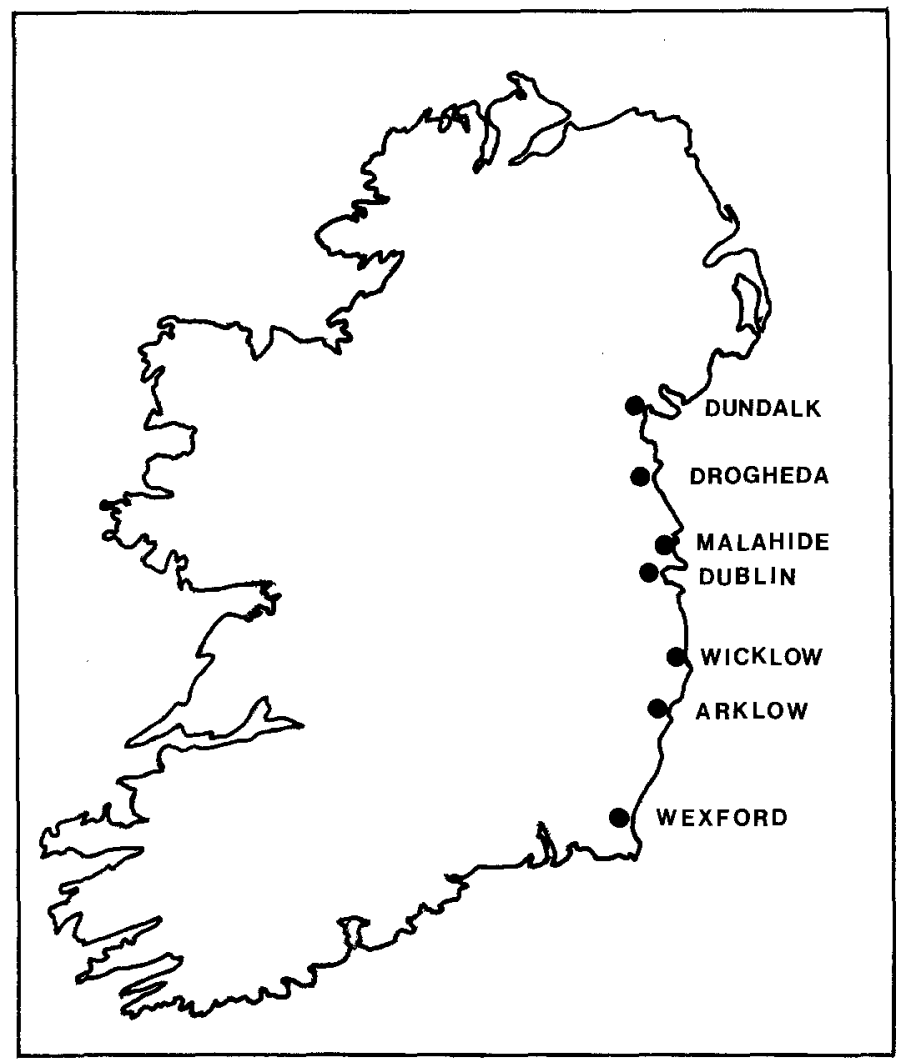

Fig. 1. Map of Eire showing major east coast estuaries

the use of organic solvents to concentrate them from large volumes of water. Secondly, metal levels in this phase are transitory, varying with the level of fresh-water inflow, tidal state, longshore drift and water and sediment chemistry, as well as other factors, such as water-sediment mixing as a consequence of wave action during storms and gales.

Consequently, to derive meaningful information from the water column frequent sampling throughout the tidal cycle and throughout the year is necessary. The combination of the required sampling frequency and problems of analysis make such investigations expensive in both chemicals and time, and in our investigations were considered to be uneconomical.

\section{The sediment}

A number of factors, many unknown or unquantifiable, affect the distribution of metals between the sediment and the water column. The total metal content of sediments often fails to reflect its availability to the aqueous phase and consequently to much of the estuarine biota. It is the exchangeable metal fraction rather than the total which frequently needs to be known for the evaluation of availability. 
The amount of exchangeable metal held in the sediment is affected by many factors. These include: (a) Particle size - in general the finer the sediment the greater the binding capacity. (b) Levels of particulate and dissolved organic matter - this may occur naturally or be introduced as sewage by $\operatorname{man}_{i}$ and its presence and quantity will differentially influence the binding of metals within the sediments. Thus Murray \& Meinke (1974) demonstrated reduced adsorption for cobalt and cadmium and increased adsorption of zinc in the presence of organic matter. In general, as the concentration of organic material in the sediment decreases towards the mouth of an estuary so also does the concentration of metals. Such a trend has been clearly demonstrated in the Liffey estuary discharging into Dublin Bay. (c) $\mathrm{pH}$ - changes in $\mathrm{pH}$, either locally within the sediment or in the water column where fresh water $(\mathrm{pH} \mathrm{6-8)} \mathrm{comes} \mathrm{into} \mathrm{contact} \mathrm{with}$ seawater $(\mathrm{pH}$ ) will differentially affect absorption of heavy metals by sediments. (d) Salinity - the effect of salinity interrelates with that of $\mathrm{pH}$ in the determination of metal solubility (Murray \& Meinke, 1974). (e) Redox - the distribution of metals between the sediment and water column is different under anoxic and oxygenated conditions, especially in the presence of sulphide. Thus copper, zinc, iron and mercury form insoluble sulphides which would tend to be bound in the sediments, and which might be released into the water column upon oxygenation.

De Groot et al. (1976) and Duursma (1976) have comprehensively reviewed the factors affecting the binding of heavy metals within sediments. Nevertheless, if one recognizes the limitations, measurement of heavy-metal content in estuarine sediments provides an approximate indication of the pollution status of the estuary.

\section{The fauna}

The use of benthic fauna as indicators of heavy-metal contamination is well established (Bryan, 1968, 1971, 1973). Species commonly used include Littorina sp., Patella sp., Mytilus edulis, Scrobicularia plana, Macoma sp., Nucella sp., and Nereis sp. All these organisms may concentrate heavy metals up to several thousand times the concentration in the water column (see Bryan \& Hummerstone, 1977). Therefore, provided sufficient material can be collected, heavy-metal concentrations can be easily and accurately established. In some benthic molluscs, however, seasonal variations in metal content have been established (Bryan, 1973). The vertical location of such organisms on the shore has also been shown to influence measured metal concentrations (Nielsen, 1974; Phillips, 1976). In most species, different metals are differentially concentrated; variations are dependent upon the size of the organism (Boyden, 1977) or the species. The method of feeding is also important (Pentreath, 1973; Schulz-Baldes, 1974; Phillips, 1976). Thus metal levels in Thais lapillus (a carnivore feeding on Balanus balanoides), Littorina littorea (a herbivore feeding on Fucus), and Mytilus edulis (a filter feeder, feeding on phytoplankton and particulate matter) will all differ from each other, and from the algae, in which the bulk of the metal loading is absorbed directly from solution (see Phillips, 1979). Presence of metals in the gut also creates difficulties and necessitates up to three days incubation in metal-free sea-water to allow evacuation of gut contents before extraction can proceed. Phillips (1979) has suggested that to obtain an accurate representation of metal levels in particular areas, the use of several indicator organisms is desirable. In intercomparisons of several estuaries, only a few common 
Table 1. Preliminary base levels for heavy metals in Fucus sp. and Mytilus edulis for east coast of Eire. Mid-sections of algae were washed in distilled water, and Mytilus edulis (shell lengths 52-57 mm) collected mid-shore in mid-winter, was incubated in clean sea-water for $72 \mathrm{~h}$ prior to analysis. Both Fucus and Mytilus were dried at $80^{\circ} \mathrm{C}$ to constant weight and the metals were extracted using hot concentrated $\mathrm{HNO}_{3}$, and metal levels were determined by atomic absorption spectroscopy. All results are expressed on a dry weight basis. Values given are means with standard deviations (s.d.). Figures in brackets indicate the number of samples analysed

\begin{tabular}{|lrrrr|}
\hline \multirow{2}{*}{ Element } & \multicolumn{2}{c}{ Fucus sp. } & \multicolumn{2}{c|}{ Mytilus edulis } \\
& $\mu \mathrm{g} \mathrm{g}^{-1}$ & \multicolumn{1}{c}{ s.d. } & $\mu \mathrm{g} \mathrm{g}^{-1}$ & \multicolumn{1}{c|}{ s.d. } \\
\hline $\mathrm{Cd}$ & 0.5 & $0.2(13)$ & 0.6 & $0.4(7)$ \\
$\mathrm{Co}$ & 0.7 & $0.2(13)$ & $\mathrm{N} . \mathrm{D}$. & \\
$\mathrm{Cr}$ & 0.4 & $0.1(12)$ & 0.3 & $0.2(7)$ \\
$\mathrm{Cu}$ & 3.8 & $0.4(24)$ & 7.0 & $0.5(8)$ \\
$\mathrm{Fe}$ & 53.0 & $17.3(17)$ & 231.0 & $54.0(7)$ \\
$\mathrm{Mn}$ & 45.0 & $9.0(19)$ & 8.0 & $2.1(7)$ \\
$\mathrm{Ni}$ & 1.2 & $0.4(15)$ & 1.0 & $0.2(7)$ \\
$\mathrm{Pb}$ & 1.3 & $0.7(20)$ & 10.0 & $2.2(7)$ \\
$\mathrm{Zn}$ & 73.7 & $7.3(24)$ & 68.0 & $9.1(8)$ \\
\hline
\end{tabular}

species are often present in sufficient numbers to provide accurate measurements of metal levels, and it is common practice to restrict collection to such species (Goldberg et al., 1978).

Despite such limitations, the estuarine fauna provides a valuable indicator for metal pollution. Baseline values for several metals in Mytilus edulis have been established for the east coast of Ireland (Table 1) and were derived simply by ranking samples in order of metal content and taking the mean of the lower $25 \%$ of the samples.

\section{The flora}

Benthic intertidal algae, particularly the larger species such as Fucus sp. and Porphyra sp., are possibly the most convenient organisms in which to measure heavymetal levels. They are stationary, extremely common, can be easily recognized, occur

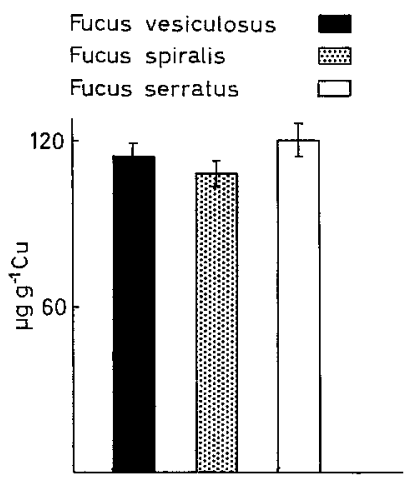

Fig. 2. Cu concentration in Fucus vesiculosis, F. spiralis and F. serratus collected from approximately the same position on the shore at Arklow (Eire) 


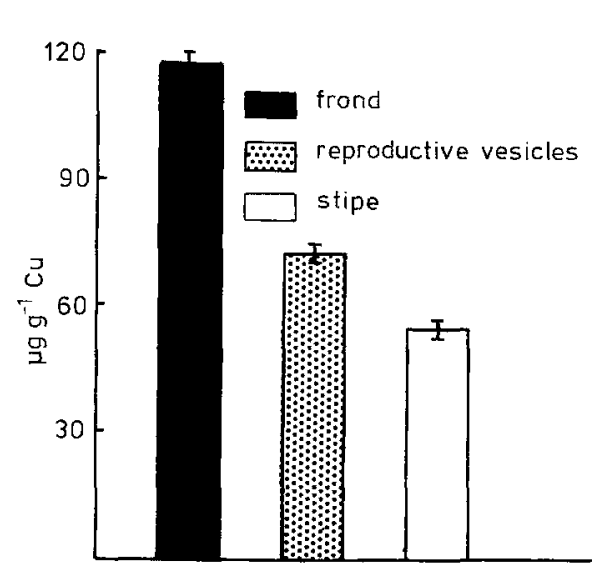

Fig. 3. Fucus serratus Histogram showing variation in $\mathrm{Cu}$ concentration in the frond, reproductive vesicles and stipe

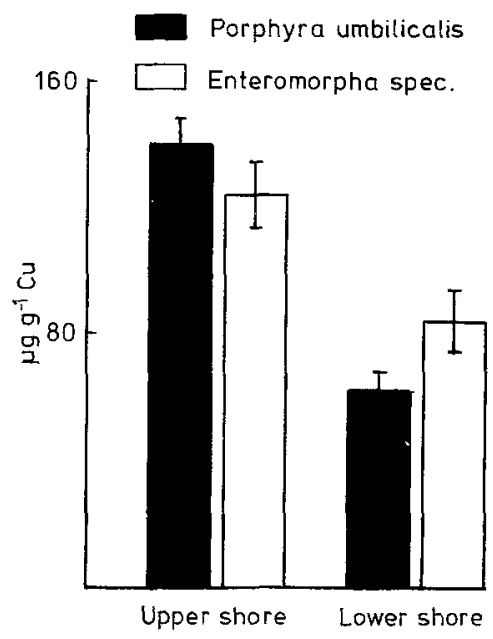

Fig. 4. Porphyra umbilicalis and Enteromorpha sp. Histograms showing $\mathrm{Cu}$ concentrations in plants collected from their highest and lowest positions on a rocky shore at Arklow (Eire)

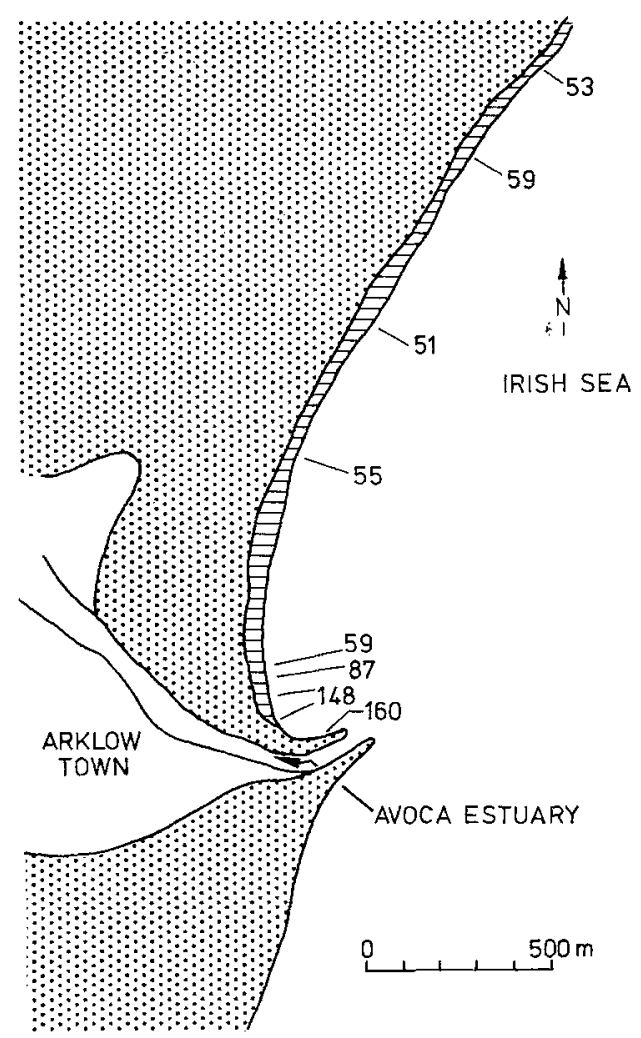

Fig. 5. Porphyra umbilicalis. Variation in copper concentration $\left(\mu \mathrm{g} \mathrm{g}^{-1}\right)$ in plants along the shoreline at Arklow (Eire) 
within well-defined zones on the shore, and concentrate metals by a factor of up to $10^{4}$ (Preston et al., 1972), with metal loadings normally directly proportional to the concentration of soluble metal in the sea-water (see Phillips, 1979). Unlike the macrofauna, there appears to be no difference in metal content with the size of Fucus (unpublished data) and F. spiralis, $F$. vesiculosus and $F$. serratus when collected from approximately the same position on the shore show no significant differences in their metal levels (Fig. 2). However, metal levels in different parts of the algal thallus do vary (Fig. 3). Thus levels in the reproductive vesicles and stipe are approximately $50 \%$ lower than in the remainder of the frond, but within the bulk of the algal thallus no differences in metal concentrations are detectable (cf. Bryan, 1971). Similarly, seasonal changes measured over a two-year period do not vary by more than approximately $25 \%$.

In our investigations, the most marked changes in metal content occurred in organisms spatially separated, either vertically or horizontally, in agreement with results of previous investigations (Bryan \& Hummerstone, 1973; Fuge \& James, 1973). Figure 4 shows copper levels in Porphyra umbilicalis and Enteromorpha sp. collected from their highest and lowest positions on a rocky shore in the Avoca estuary at Arklow. Significant differences are apparent.

Similarly, Figure 5 shows copper levels in Porphyra at sites along the shore. The copper levels can be seen to fall dramatically over a distance of only approximately 250 $\mathrm{m}$. Base-line metal concentrations have been derived for the common intertidal algae in the same way as for the macrofauna, and those for Fucus sp. along the east coast of Ireland are shown in Table 1.

\section{Indices for pollution assessment}

The Irish Estuarine Research Group has devised two indices which describe the quality of an estuary in terms easily understood by the non-specialist and which can be used to compare the pollution status of different estuaries. The first of these, the Biological Quality Index (BQI) is a simple index based upon the relative areas of the estuary covered by "normal," opportunistic and abiotic regions. "Normal" areas are characterized by high species diversity, opportunistic zones are occupied by accepted pollution indicator species (e.g. Capitella capitata), and abiotic zones, normally characterized by black, anaerobic mud, are areas supporting only microbiota. An arbitrary value of 10 is assigned to an unpolluted estuary, and percentage areas occupied by opportunistic and abiotic zones are substracted. In this scheme, abiotic zones are given a weighting factor of 10 in recognition of their serious state of deterioration.

Thus BQI $=10-b-10 a$, where $a=$ proportion abiotic, $b=$ proportion opportunistic.

Figure 6 illustrates the use of this scheme on three hypothetical estuaries. On the left is a pollution-free estuary having a $\mathrm{BQI}=10$. In the centre, $10 \%$ of the estuary is abiotic and $20 \%$ opportunistic giving a BQI of 8.8 , and on the right hand side $30 \%$ of the estuary is abiotic and $20 \%$ opportunistic, giving a BQI of 6.8 .

The use of such an index, whilst requiring the ability to identify pollution indicators and extensive sampling, nevertheless gives a simple means of comparing the biological quality of one estuary with another.

The second index proposed is the Pollution Load Index (PLI) obtained by uniformly sampling intertidal algae or fauna within an estuary, measuring their metal contents and 


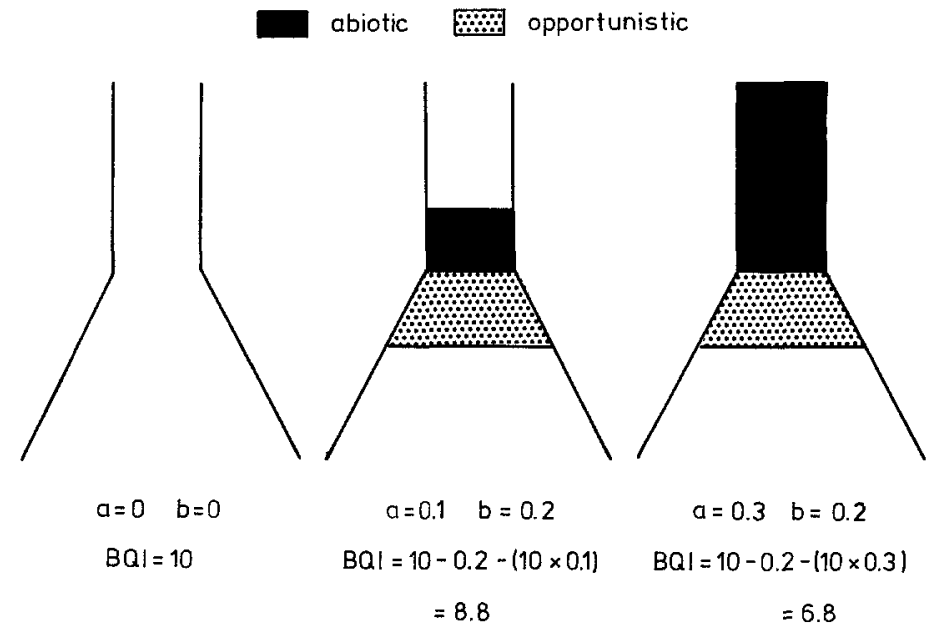

Fig. 6. Application of the Biological Quality Index (BQI) to three hypothetical estuaries

deriving contamination factors by reference to the baseline metal levels quoted in Table 1. The contamination factor (C.F.) for each metal equals concentration of metal in organism/base value for that metal. A number of contamination factors will be derived for different metals at each site, and a site pollution index may then be calculated by taking the five highest contamination factors and deriving the fifth root of the five factors multiplied together. Such site indices can be treated in exactly the same way to give a zone index, and thence an estuary index from the zone indices. Therefore, Pollution Load Index (PLI) for site $=\sqrt[n]{\mathrm{CF}_{1} \times \mathrm{CF}_{2} \ldots \times \mathrm{CF}_{\mathrm{n}}}$, Pollution Load Index for zone $=\sqrt[n]{\text { site }_{1} \times}$ $\overline{\text { site }_{2} \ldots \times \text { site }_{n}}$ and Pollution Load Index for the estuary $=\sqrt[n]{\text { zone }_{1} \times \text { zone }_{2} \ldots \times \text { zone }_{n \prime}}$ where $n$ equals the number of contamination factors, sites and zones respectively.

The use of such an index in simplified form is illustrated in Figure 7. The estuary is divided into three zones of approximately equal area. Each zone would normally consist of a number of sites, but in this example only one site is given for each zone. Contamination factors for $\mathrm{Cu}, \mathrm{Pb}, \mathrm{Zn}$ and $\mathrm{Ni}$ are used to produce site and zone indices, and these indices are then multiplied and cube rooted to give the Pollution Load Index for the estuary. Figure 8 illustrates such indices using Fucus sp., calculated for the east coast estuaries. This shows clearly that the Avoca estuary at Arklow is by far the most polluted with regard to heavy metals, whereas Malahide and Dublin are the least polluted.

From the calculated indices, a coastal index of 2.2 has been derived. This has been checked against the data of Preston et al. (1972) who also measured metal levels in Fucus sp., along the east coast of Ireland, albeit at different sites. A coastal pollution index of 1.95 may be derived from their data, in good agreement with the index proposed by our group.

Pollution Load Indices have also been derived using published data for the Bristol Channel (Fuge \& James, 1974), the Looe Estuary, Cornwall (Bryan \& Hummerstone, 1977) and a polluted (Sørfjorden) and unpolluted (Reine in Lofoten) estuary in Norway (Melhuus et al., 1978). Values of 3.8, 7.4, 29.0 and 3.1, respectively, suggest that with the exception of the copper polluted Avoca estuary at Arklow (Fig. 8), the east coast 


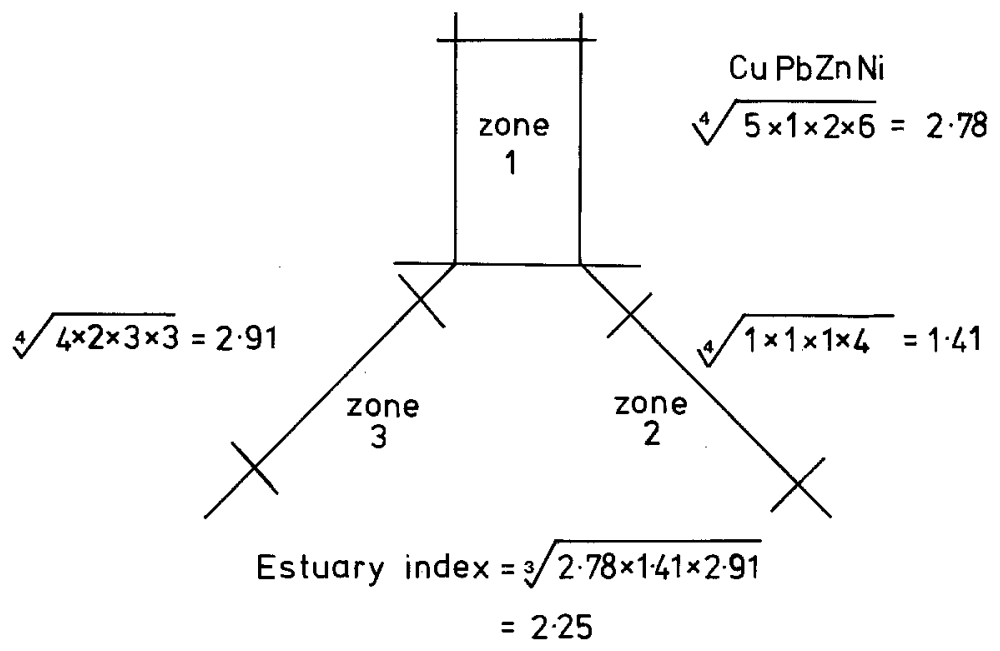

Fig. 7. Application of the Pollution Load Index (PLI) to a hypothetical estuary

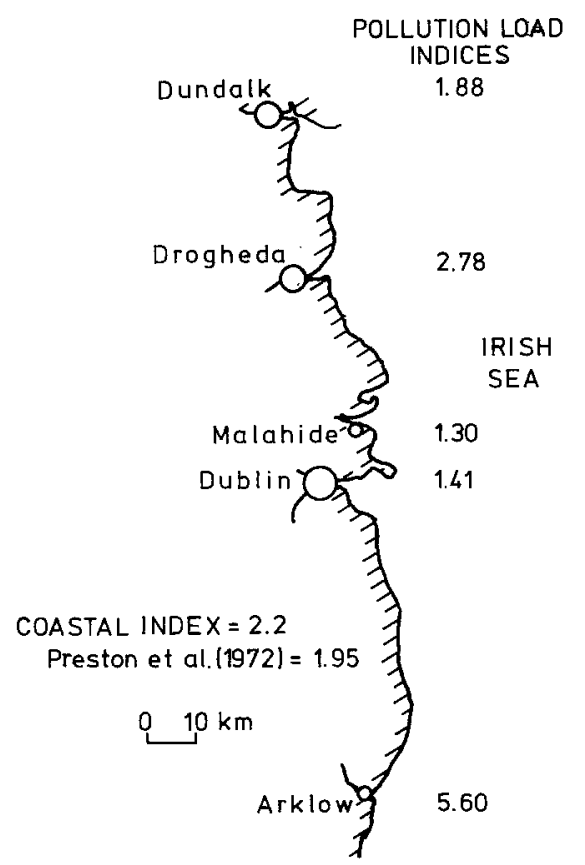

Fig. 8. Pollution Load Indices for estuaries along the east coast of Eire, together with the derived coastal index and similar index calculated from the data of Preston et al. (1972)

estuaries of Ireland compare favourably in terms of metal pollution, with these coastlines.

It is recognized that different metals will have variable toxicity levels to estuarine organisms, which is, in part, dependent upon the chemical form of the metal in solution. Trace metal availability and toxicity is often a function of the free metal ion, which in 
turn is dependent upon the nature of both organic and inorganic ligands in the medium (see Engel \& Fowler, 1979). Thus the concentration of free cadmium ion in solution has been shown to vary inversely with salinity owing to complexation with chloride ions (Sunda et al., 1978). It is likely that other trace metals behave in the same way so that availability to the estuarine biota may often be dependent upon the salinity of the surrounding medium.

In addition to chemical speciation affecting the toxicity of a particular metal, different metals have variable toxicities to different organisms. Reish (1978) assessed the lethal and sub-lethal effects of six metals on polychaetous annelids. In survival experiments, the order of decreasing toxicity was mercury (0.1 to $0.09 \mathrm{mg} / \mathrm{l})$, copper $(0.16$ to 0.3 $\mathrm{mg} / \mathrm{l}$ ), chromium (3.12 to $5.0 \mathrm{mg} / \mathrm{l})$, zinc (1.8 to $10.7 \mathrm{mg} / \mathrm{l})$, cadmium (4.2 to $20 \mathrm{mg} / \mathrm{l})$ and lead $(7.7$ to $20 \mathrm{mg} / 1)$, and in all cases, larval phases were more sensitive than the adults. The use of data from such bioassays is essential for the establishment of mathematical weights based upon differential toxicity of different pollutants, which could be used to improve the Pollution Load Index.

It is recognized that unusually high levels of a single pollutant might result in an unusually low index value if other pollutants in the system were present at near baseline concentrations. Such a fault might be overcome by using a subscript to the index identifying any pollutants present in abnormally high concentrations. Thus the index for the Avoca Estuary at Arklow (Fig. 8) would become 5.6 $6_{\mathrm{CuZn}}$, indicating that copper and zinc were the major pollutants giving rise to the relatively high Pollution Load Index for this estuary.

The index as presented provides a simple, comparative means for assessing estuarine quality: a value of zero indicates perfection, a value of one that only baseline levels of pollutants are present, and values above one would indicate progressive deterioration of estuarine quality. Whilst an index value cannot at present provide information on the effects of the combination of pollutants on the estuarine biota, it can provide the public with some understanding of the quality of a component of their environment, and it can indicate trends over time and area. In addition, it is envisaged that all information necessary for the construction of a Pollution Load Index would be readily available to specialists who could analyse the key components which together give rise to an index value, and thereby provide advice to the administrator who is then better able to understand the effects of policy decisions on estuarine quality.

Despite the above-mentioned flaws, and the necessity to achieve some improvement of the proposed indices, it is suggested that the use of the Biological Quality Index and the Pollution Load Index provide a means for quantifying estuarine quality in the simplest way, and are thus comparable with similar indices used for assessing air and fresh-water quality (Thomas, 1975).

\section{LITERATURE CITED}

Boyden, C. R., 1977. Effect of size upon metal content of shellfish. - J. mar. biol. Ass. U. K. 57, $675-714$

Bryan, G. W, 1968. Concentrations of zinc and copper in the tissues of decapod crustaceans. - J. mar. biol. Ass. U. K. 48, 303-321.

Bryan, G. W., 1971. The effects of heavy metals (other than mercury) on marine and estuarine organisms. - Proc. R. Soc. (B) 177, 389-410. 
Bryan, G. W., 1973. The occurrence and seasonal variation of trace metals in the scallops Pecten maximus (L.) and Chlamys opercularis (L.). - J. mar. biol. Ass. U. K. 53, 145-166.

Bryan, G. W. \& Hummerstone, L. G., 1977. Indicators of heavy-metal contamination in the Looe Estuary (Cornwall) with particular regard to silver and lead. - J. mar. biol. Ass. U. K. 57, 75-92.

Crisp, D. J., 1976. Survey of environmental conditions in the Liffey Estuary and Dublin Bay. Unit of Marine Invertebrate Biology, Marine Science Laboratories, Menai Bridge, Gwynedd, U. K., 74 pp.

Duursma, E. K., 1976. Radioactive tracers in estuarine chemical studies. In: Estuarine chemistry. Ed. by J. D. Burton \& P. S. Liss. Academic Press, London, 159-183.

Engel, D. W. \& Fowler, B. A., 1979. Factors affecting cadmium accumulation and its toxicity to marine organisms. - Environ. Hlth Perspect. 28, 81-88.

Fuge, R. \& James, K. H., 1974. Trace metal concentrations in Fucus from the Bristol Channel. - Mar. Pollut. Bull, 5, 9-12.

Goldberg, E. W., Bowen, U. T., Farrington. J. W., Harvey, G., Martin, J. H., Parker, P. L., Risebrough, R. W., Robertson. W., Schneider, E. \& Gamble, E., 1978. The mussel watch. - Environ. Conserv. $5,1-25$.

Groot, A. J. de, Salomans, W. \& Allersma, E., 1976. Processes affecting heavy metals in estuarine sediments. In: Estuarine chemistry. Ed. by J. D. Burton \& P. S. Liss. Academic Press, London, 131-157.

Melhuus, A., Seip, K. L., Seip, H. M. \& Myklestad, S., 1978. A preliminary study of the use of benthic algae as biological indicators of heavy metal pollution in Sørfjorden, Norway. - Environ. Pollut. $15,101-107$.

Murray, C. N. \& Meinke, S., 1974. Influence of soluble sewage material on absorption and desorption behaviour of $\mathrm{Ag}, \mathrm{Cd}, \mathrm{Co}$ and $\mathrm{Zn}$ in sediment-sea water system. - J. oceanogr. Soc. Japan 30, 216-221.

Murray, C. N. \& Murray, L. 1973. Absorption-desorption equilibria of some radionuclides in sediment-fresh water and sediment-sea water systems. In: Radio-active contamination of the marine environment. I. A. E. A., Vienna, 105-124.

Nielsen, S. A., 1974. Vertical concentration gradients of heavy metals in cultured mussels. - N.Z.JI mar. Freshwat. Res. 8, 631-636.

Pentreath, R. J., 1973. The accumulation from water of $\mathrm{Zn}^{65}, \mathrm{Mn}^{54}, \mathrm{Co}^{58}$ and $\mathrm{Fe}^{59}$ by the mussel Mytilus edulis. - J. mar. biol. Ass. U. K. 53, 127-143.

Phillips, D. J. H., 1976. The common mussel Mytilus edulis as an indicator of pollution by zinc, cadmium, lead and copper. I. Effects of environmental variables on uptake of metals. - Mar. Biol. $38,59-69$.

Phillips, D. J. H., 1979. Trace metals in the common mussel, Mytilus edulis (L.), and in the alga Fucus vesculosus (L.) from the region of the sound (Oresund), - Environ. Pollut, 18, 31-41.

Preston, A., Jefferies, D. F., Dutton, J. W. R., Harvey, B. R. \& Steele, A. K., 1972. British Isles coastal waters: The concentrations of selected heavy metals in sea water, suspended matter and biological indicators - a pilot survey. - Environ. Pollut. 3, 69-82.

Reish, D. J., 1978. The effects of heavy metals on polychaetous annelids - Revue int. Océanogr. méd. $49,99-103$.

Schulz-Baldes, M., 1974. Lead uptake from sea-water and food, and lead loss in the common mussel Mytilus edulis - Mar. Biol. 25, 177-193.

Sunda, W. G., Engel, D. W. \& Thuotte, R. M., 1978. Effect of chemical speciation on toxicity of cadmium to grass shrimp. Palaemonetes pugio: Importance of free cadmium ion. - Environ. Sci. Technol. 12, 409-413.

Thomas, W. A., 1975. Indicators of environmental quality. Plenum Press, New York, 275 pp. 